\title{
The influence of the effectiveness of teaching at the university on the motivation of the pedagogical career of graduates (Bulgarian example)
}

\author{
Nataliya Alexandrova ${ }^{1}$ and Liliya Babakova ${ }^{2 *}$ \\ ${ }^{1}$ International Buisness School, Botevgrad, Bulgaria \\ ${ }^{2}$ Academy of Music, Dance and Fine Arts, Plovdiv, Bulgaria
}

\begin{abstract}
One of the main problems nowadays in Bulgaria is the status of teachers. Improving and accentuating the prestige of the teaching profession is one of the main goals in the education policies of Bulgaria. To achieve this goal, a deeper consideration and knowledge of the motivation of students in pedagogical profiles to start a career in the field of school education is needed. The aim of this study is to determine how teaching effectiveness in university influences the motivation of students in pedagogical profiles to become teachers after they have graduated. This article presents a study of the relationship between the teaching effectiveness at university and the attitudes of students who are trained in profiles with a pedagogical focus on the teaching profession. 85 students from pedagogical field of study have been studied and the results of regression and ANOVA analysis are discussed.
\end{abstract}

\section{Introduction}

In recent years, there has been a strong drive to seek ways and strategies to improve the prestige and quality of the teaching profession. However, there is a shortage of teachers and difficulties in recruiting and selecting new education staff who are highly skilled and prepared for the challenges of today's education. Much of the teachers in the school are in pre-retirement age, and there is generally a tendency towards aging of the current workforce in school education, both nationally and globally [1,2].

That is why it is important to find out what motivates people to look favorably at a teaching career at school and, on this basis, to draw up policies related to attracting more staff in this field. For this purpose, it is also necessary to know the motivational models and strategies in the management of education [3]. Currently, the situation in Bulgaria is such that there are many young people who have completed their education, which gives them the ability to work as teachers, but few are the ones who need to take up this profession immediately after graduation.

\footnotetext{
* Corresponding author: babakova.lilya@gmail.com
} 


\section{Theoretical Framework}

\subsection{Current state of pedagogical training of future teachers in Bulgaria and demotivational factors on the path to the teaching profession}

At present, in Bulgaria, the teaching profession can be practiced by people who have graduated from a bachelor's program, a master's degree program or a specialization in which certain disciplines are studied which form the professional skills of teachers psychology (general and age, pedagogical psychology), pedagogy (history of education, theory of education, didactics), teaching methods, inclusive education, audiovisual and information technologies in education.

Although many students study these disciplines during their studies, few of them are professionally oriented in the field of school education. The reasons for this are many, but what stops young people from choosing this profession is that it is not attractive enough, there is a high workload and stressfulness. They are studies that found that the teaching profession is one of the most stressful, and this in turn is a prerequisite for an emotional burnout. There are six areas that make teachers vulnerable to the development of burnout and demotivation: workload, performance control, reward, community, equity and shared values in the organization [4].

\subsection{Factors determining the choice of the teacher profession.}

Choosing a profession as a school lecturer is conditioned by many factors. With good government policies, the gradual increase in teacher salaries over the last few years, job security could have an impact on the demand for potential staff in the field of education. In some countries like Taiwan, teaching in school as a profession has a high status, although salaries are relatively low [5]; in Germany, teacher rewards are much better than other jobs, but the status is low [6]. In Turkey, the work of teachers is perceived as respectful, although remuneration in this area is not high, but there is an important factor in security at work [7].

That is not the case in Bulgaria. There is a tendency to lower the professional sustainability of future teachers. In order to prevent this, the students should enter into their future professional and pedagogical activity from the first course in any occupation of the studied pedagogical disciplines [8].

\subsection{The student perception of teaching effectiveness at university as a predictor for choosing a teaching profession}

One key external motive for the choice of the teaching profession is the student perception teaching effectiveness at university. One of the goals of higher education is to encourage students to study, but training itself involves more components than merely exposing information. The audience is a multidimensional environment in which psychological and social interactions predominate in different groups of the academic community. According to some authors, the social environment in which students are learning and the teaching effectiveness at university can influence their attitudes, behaviors, self-esteem and overall satisfaction [9]. That is why the positive experience that students receive in the higher school is also important. Some well-motivated teachers or attractive courses in pedagogical disciplines (psychology, pedagogy, and teaching methodology) at the university can be a model for students to pursue a teaching activity when they have graduated. The teaching effectiveness at university and academic environment of students (learning load, quality of teaching, interaction with lecturers) can be a significant factor for students to pursue the teaching profession when they have graduated. 


\section{Purpose of the Study and Hypotheses}

\subsection{The aim of research}

The aim of this research is to study the impact of effective teaching at university on the motivation of students to become teachers. Such a study is important because the establishment of such a relationship could help to systematise different aspects and characteristics affecting the motivation, attitudes and perceptions that students have for the teaching profession and consequently to make recommendations for the improvement of university courses and teaching methods that stimulate, prepare and motivate young people to become teachers when they complete higher education.

\subsection{Hypothesis:}

- We have assumed that students who have positive perceptions of effective teaching will be more motivated to work with children and students.

- It is supposed that female have a higher motivation to become teachers, because in Bulgaria this profession is feminized.

- It is assumed that students will be more motivated to work in kindergarten or elementary school, as there are more hours of music and fine art in these two stages of learning.

\section{Methodology}

\subsection{Instruments}

The "FIT-Choice" scale [6], which consists of three parts: factors of influence on students' attitudes to become teachers; educational beliefs; decision to choose a teacher's career. The scale has good psychometric values for the Bulgarian sample of students for the following subscales: teaching abilities (ex. "I have qualities to become a good teacher"; $\alpha=0.738$ ), intrinsic motivation (ex. "I like to teach"; $\alpha=0.938$ ), job security (eg, "Teaching offers a permanent career"; $\alpha=0.876$ ), time for the family ("As a teacher I will have long vacations"; $\alpha=0.840$ ) work with children and adolescents ("I like working with children and adolescents "; $\alpha=0.957$ ), shaping the future of children and adolescents ("As a teacher, I will be able to formulate certain values in children and adolescents"; $\alpha=0.818$ ), improving social justice (etc. "As a teacher, I can encourage disadvantaged young people to achieve their goals"; $\alpha=0.870$ ), social contribution ("As a teacher, I can be useful for society"; $\alpha=0.815$ ), salary (etc. "I think that the work of teachers is currently well paid"; $\alpha$ $=0.958)$, expertise ( $\mathrm{pr}$. "I believe that teachers need a high level of technical knowledge"; $\alpha=0.824$ ), social status (ex. "I think that the teacher is respected"; $\alpha=0.831$ ), previous teaching / learning experience ("I had good teachers"; $\alpha=0.915$ ), social influences (etc. "My family thinks I should become a teacher"; $\alpha=0.832$ ), satisfaction with the choice of a profile with the qualification of a teacher (etc. "I would be happy if I became a teacher"; $\alpha$ $=8.880)$.

The students evaluation of teaching effectiveness scale [10]. The original version of this scale contains 21 items, whose semantics are related to the organization and clarity of teaching, dynamics and interest of teaching, interaction with students. The Bulgarian version of this scale contains 17 items, divided into one scale $(\alpha=0.957)$.

\subsection{Participants of study}


The respondents to the study are 85 first-year students studying the profiles "Music" and "Fine Arts" at the Pedagogical University. Of these, $42 \%$ are men, $58 \%$ are women. $68 \%$ of them study the profile "Music Education" $31 \%$ noted that they study the profile "Education of fine art" In the demographic profile, $28 \%$ of students indicated that they want to work in kindergarten after graduation, $29 \%$ want to be implemented in primary stage of education, $17 \%$ want to work in high school, and $25 \%$ want to create their own private school.

\section{The Results of the Study}

\subsection{Influence of "gender", "major" and "area of implementation of the education system"on the motivation for choosing a teaching profession and perceived effective assessment of teaching at university}

ANOVA analysis revealed statistically significant differences between the factors "gender", "profile" and "stage of teaching at school" and individual subsets on the FIT-Choice scale. Using the Fisher F-test, it was found that "gender" influences significantly (the p-criterion is an indicator for a statistically significant difference) in the subscales "Forming the future of children and adolescents" $(\mathrm{F}(1526.469)=10.293 ; \mathrm{p}=0.002)$, "Improving social justice ” $(\mathrm{F}(865,282)=7,480, \mathrm{p}=0,008)$, “ Internal motivation ” $(\mathrm{F}(405,250)=5,285, \mathrm{p}=0,024)$ and" Social contribution " $(\mathrm{F}(2,159,361)=5,250 ; \mathrm{p}=0.024)$. Females have higher values for these subscales. For all other subscales, there were no statistically significant differences in the gender factor.

According to the factor "stage of teaching at school" it was found that students who want to work in kindergarten and elementary school have higher values on the scale of "work with children and adolescents" than those who want to develop in high school or in private school $(\mathrm{F}(450586)=2,502 ; \mathrm{p}=0,056)$. According to the subscale "Previous Teaching / Learning Experience", it is noted that those who want to work in elementary school, and to a lesser extent those who want to work in a private school, have higher values than those who want to work in kindergarten and in high school (F (496 493) = 2.604; $p=0.059$ ). The "Salary" subscale showed high values for those students who would like to work in primary school, compared with those who want to be realized as a teacher in a kindergarten, gymnasium or in a private school $(\mathrm{F}(304,265)=2,556, \mathrm{p}=0,052)$

The subscale "Satisfaction with the choice of a pedagogical profile" shows that the highest values are typical for students who would like to work in kindergarten and elementary school, and the lowest - for those who want to work in high school and in a private school $(\mathrm{F}(456,756)=2,883, \mathrm{p}=0,044)$. According to the factor "Profile", we found that students who chose the profile "Fine Arts" had higher values than students studying "Music education" on the following scales: "Improving social justice" (F $(501,090)=10,682, p=0.002)$ and "Intrinsic motivation" $(F(223.271)=5.084 ; p=0.027)$.

As for the scale "Assessing the effectiveness of teaching at a university", only one statistically significant difference was found - on the factor "the stage of teaching at school". Students who prefer to work in kindergarten or elementary school have higher values on this scale than those who would like to teach in high school or in private schools $(\mathrm{F}(273.195)=4.348, \mathrm{p}=0.01)$. It can be assumed that music and visual arts classes are primarily provided for in the curriculum of preschool or elementary school students and are relatively less in high school. For all other factors, significant statistical differences on the scale of "Perceived effective assessment of university studies" were not found.

\subsection{Impact of perceived effective assessment of teaching on motivation to attitude of teaching carrer}


The analysis of linear regression showed that effective teaching at the university has a positive effect on the subscales "Shaping the future of children", "Previous experience in teaching / learning", and "Satisfaction with the choice of a pedagogical profile", and negatively on the subscales: "Learning abilities", "Work with children and adolescents "and" Social Contribution". There were no statistically significant relationships with the subscales "Intrinsic motivation", "Improving social justice", "Job security", "Social status" and "Salary". The results of the analysis of linear regression showed that the coefficient of mutual determination is high $(\mathrm{R} 2=0.624)$, which means that the independent variable "assessment of teaching effectiveness" can be $62.4 \%$ of the variance of dependent variables. However, $37.6 \%$ of the variations remain unexplained, which implies the presence of other additional variables that play an important role in the interpretation of motivational characteristics regarding the choice of a teacher's carrer, but which are not the subject of this study.

The regression analysis, and in particular the $\beta$-coefficients, which show the strength of the effect of effective teaching on the FIT-Choice subscales, testifies to the fact that a high assessment of teaching and effective learning at the university positively affects the scale "Work with children and adolescents" $(\beta=0.491 ; p=0.042)$. Students report that educational study at the university, and in particular pedagogical disciplines, is worthy to be done. When a teacher or study material in a university is perceived as a value, students themselves feel that they can influence the future as a teacher on their students. In addition, students who evaluate the quality of teaching at the university report high values for the subscale "Previous teaching / learning experience", that is, effective teaching at the university is associated with positive teaching or learning experience in the past $(\beta=0.482$; $\mathrm{p}=0.021$ )

In addition, students who highly evaluate their teachers and consider their pedagogical approaches effective demonstrate high values on the Expertise scale $(\beta=0.537 ; p=0.003)$, that is, students believe that these learning models, which they see in their teachers are successful and useful for mastering knowledge. A higher assessment of teaching at the university is positively associated with the subscale "Satisfaction with the choice of teacher education and teacher career" $(\beta=0.505 ; \mathrm{p}<0.001)$. The perception of good teaching methods at the university and the effectiveness of teaching are necessary conditions for students to experience a high degree of satisfaction with the chosen pedagogical profile.

Nevertheless, a high rating of effective teaching at the university negatively affects the subscale "Teaching Abilities" $(\beta=0.430 ; p=0.013)$. The reason for this may be the fact that the study was conducted among first-year students, for whom the transition from school to university is new. The high academic level of teaching, many of the terms that are taught at the university, new educational study are likely to make students feel uncertain that they will be able to cope with the new academic requirements and that they will be able to work as teachers. Students who appreciate the high level of teaching at the university have low values for the subscale "Shaping the future of children and adolescents" ( $\beta=$ $0.510 ; \mathrm{p}=0.007)$, and also do not believe that teaching can make a "Social contribution" to society $(\beta=-0.539 ; p=0.052)$. High academicism and the lack of career guidance in the early stages of higher education, as well as the low status of teachers in society are the reason for student's showing negative attitude for these subscales.

\section{Discussion and conclusions}

The purpose of this study was to determine whether effective university education is a factor encouraging students to choose the teaching carrer. We suggested that students who see a good learning pattern of their teachers or an incentive to learn will be more motivated to become teachers. 
The quality of teaching university lecturers is an important factor determining the choice of students to become teachers after graduation. Current empirical findings about the desire of young people to become teachers when they see a good and effective example of teaching at the university show that the model of effective teaching at the university is a key factor in choosing a teaching career in the future. The results of our study show that students who evaluate highly teaching at the university are focused on the teaching career, primarily because they believe that they can affect the future of children and adolescents. These people are very pleased with their choice to study a pedagogical profile and are striving to improve their knowledge and skills on the path to a career.

In addition, students believe that at the university they can gain experience and ability to work as teachers. Effective teaching at the university affects the choice of a student's teaching career, that is, the pattern of learning that students see with their teachers is a prerequisite for achieving positive motivation to work as teachers. But the results of the regression analysis that were obtained during the study do not show a high tendency to a decisive choice of a pedagogical career. This is probably due to the fact that we did a study among first-year students who are still at the beginning of their studies at the university and have not studied most of the pedagogical disciplines that will form the ability to teach.

In the course of this study, it was found that the choice of a teaching career prevails among females, and the most preferred stages of teaching are primary school and kindergarten. Thus, our second and third hypotheses are fully confirmed. In the future, efforts must be made to improve the social status of teachers. High salaries will also lead to an increase in demand for teacher profiles.

Regarding the quality of teaching at the university, this study suggests that work can be done to improve the curriculum in order to prevent students from losing interest in pedagogical disciplines and choosing other profiles. Therefore, it is necessary to make effective curricula and take into account the goals and objectives that are set before the university, as well as the intellectual and creative abilities of students. Whenever possible, the students' choice of pedagogical subjects that are most interesting to them and best suits their needs should be taken into account.

This study also has limitations. The sample is too small to argue that the teaching pattern of university teachers is the main factor determining teacher choice. In addition, the study was conducted among first-year students who probably do not have a specific career attitude.

\section{References}

1. NSI report (2019)

2. P.W. Richardson, H. M. G. Watt, Asia-Pacific Journal of Teacher Education, 34 (1), (2006)

3. E.M.Kats, The Third international conference "Innovative strategies in higher education" (Sofia, 2006)

4. R. Zaharieva, Stress in the teacher's profession - Third National Conference (2012)

5. H. H. Wang, International Journal of Science Education, 26, (2004)

6. H. M. G. Watt \& P. W. Richardson, Journal of Experimental Education, 75, (2007)

7. A.Kılınç, H.M.G Watt \& P.W. Richardson, Asia-Pacific Journal of Teacher Education, 40, (2012)

8. M. Nikolova, M. Ingilizova, Pedagogical Forum (2015)

9. J.J. Barr, IDEA Paper, 61 (2016)

10. L. Harvey \& M. Hébert, Mesure et évaluation en éducation, 35, 3 (2012) 